\title{
Effect of altitude on the emission characteristics of a DI diesel engine
}

\author{
Wei Zhao ${ }^{1, *}$, Yunshan $\mathrm{Ge}^{2}$, Jingyuan $\mathrm{Li}^{1}$, Le $\mathrm{Liu}^{1}$, and Yuwei Wang ${ }^{1}$ \\ ${ }^{1}$ Testing Laboratory, China Automotive Technology and Research Center Co., Ltd., Tianjin 300300 \\ ${ }^{2}$ School of Mechanical Engineering, Beijing Institute of Technology, Beijing 100081
}

Keywords: diesel engine, altitude, combustion, emission.

\begin{abstract}
To evaluate the effects of altitude on common rail electronic-controlled diesel engine, an experiment was carried out on a test bench with the simulated altitude system. The results indicated that the emissions of $\mathrm{CO}$ and Soot increased, while the impact of altitude on NOx varied based on the specific loads and speed when altitude increased from $0 \mathrm{~m}$ to $4000 \mathrm{~m}$. The increment rate of $\mathrm{CO}$ and Soot increased with altitude, and the impact of altitude was greater on CO and Soot than those of NOX. The average emissions of $\mathrm{CO}$ and Soot increased with altitude, while the average emission NOx first increased at $1000 \mathrm{~m}$ then decreased with altitude. The average increasing rate of $\mathrm{CO}$,Soot and NOx was $14.5 \% \sim 59.5 \%, 13.4 \% \sim 25.6 \%,-5.6 \% \sim 0.5 \%$ respectively.
\end{abstract}

\section{Introduction}

Mobile sources are one category of the most relevant air toxic emission source to outdoor human activities in industrialized societies (EPA, 1990)[1-3]. Besides engine type, fuel property, the vehicle emissions also depend on topography and climatic conditions (e.g. altitude, humidity, temperature). Altitudes impact the temperature and pressure inside of the engine which in turn lead to altitude-induced changes in diesel combustion and emission characteristics. To make accurate assessment about the contribution of vehicle' emissions to air pollution and take effective measure to control the vehicle emissions, an accurate emission inventory based on the emission factors should be established first. Therefore it is very important to investigate the effect of altitude on diesel engine, and it is especially necessary to china. The area of altitude above $2000 \mathrm{~m}$ accounts for $33 \%$ and $16 \%$ for the altitude above $3000 \mathrm{~m}$ in China, the important cities located in high altitude such as Kunming (1900m), lijiang (2400m) Xi-ning(2295m) and Lhasa(3650m) are all tourist cities, and the development of these cities depends on the air quality. However, the effect of striker regulation may be weakened due to the specificity of the location of these cities, even worse, the total emissions and contribution of high altitudes to the air pollution may larger than those of inland cities due to the increment of vehicle population. Therefore it is very useful for establishing emission modes based on the emission factors and evaluating the contribution of the vehicle to air pollution. Meanwhile, the study can also help air

\footnotetext{
* Corresponding author: zhaowei01@catarc.ac.cn
} 
quality control authorities to design future mitigation strategies for controlling vehicle emissions of high altitude and keeping the sustainable development of cities.

The atmospheric pressure and oxygen content decrease with the increment of altitude, which is the main factor affected the performance (power, torque, efficiency and specific fuel consumption) of the engine, especially the combustion condition of the engine, and the representative study in this filed was carried out by Lizhong Shen[4,5] and Agudelo[6,7]. In addition to combustion, exhaust emissions from diesel engines at high altitude are of concern. The experimental works are usually conducted by altitude simulation system, which is usually achieved by adjusting the pressure of inlet air and exhaust. Studies showed that the emissions of $\mathrm{CO}$, smoke and particulate matter generally increased with altitude, while NOX varied based on the engine type, operation and altitudes. Southwest Research Institute (SRI) used altitude simulation Constant Volume System (CVS) to evaluate the emissions from a naturally aspirated and a turbocharged diesel engine. The results (Human et al., 1990) indicated at $1800 \mathrm{~m}$ the nitrogen oxides (NOX) reduced by $10 \%$ for both engines [8]. The same turbocharged diesel engine was tested by Graboski and McCormick to investigate the fuel properties on diesel emissions at $1609 \mathrm{~m}$, and the similar conclusion was drawn that NOX emissions were not effected by altitude during the heavy-duty transient test[9]. Bishop et al(2001) used on-road measurements tested 5772 heavy-duty diesel trucks emissions of $\mathrm{HC}, \mathrm{CO}$ and $\mathrm{NOX}$ at five locations which altitude varied from $104 \mathrm{~m}$ to $2530 \mathrm{~m}$, and they reported that the NOX emissions showed slightly increase with altitude[10]. . Shen et al. (2006) also reported that NOX increased with increasing simulated altitude. Chao he et al(2011) have investigated emission conditions at simulated altitude from 0 to $2000 \mathrm{~m}$ for turbocharged engine, and the results indicated that the NOX varies with engine types and operation conditions[4,11]. From the literature it can be known that the studies focus on NA or traditional turbocharged engine performance at $0 \sim 2000 \mathrm{~m}$, while there is few papers reported the effect of altitude on emissions conditions of electric common-rail diesel engine. As it known to us that the common rail has become the necessary part to match the Euro- IV or striker pollution regulations. In this paper the electric common-rail diesel was studied and the altitude was varied from 0 to $4000 \mathrm{~m}$ cover most altitudes of the metropolises.

\section{Test engine}

Test herein using heavy duty diesel engine is a state IV, which parameters are shown in Table 1, the test fuel parameters shown in Table 2.

Table 1. Engine specifications.

\begin{tabular}{cc}
\hline Reference & \\
\hline engine type & 4-strokes, direct injection Electronically Controlled Common-Rail \\
Air intake system & Turbocharged, inter-cooled, \\
Configuration & 6 In-line cylinders \\
Diameter & $112 \mathrm{~mm} \times 145 \mathrm{~mm}$ \\
Displacement & $8.6 \mathrm{~L}$ \\
Rated Power & $258 \mathrm{~kW}$ at $2100 \mathrm{r} / \mathrm{min}$ \\
Maximum Torque & $1500 \mathrm{Nm}$ at $1200 \mathrm{r} / \mathrm{min}$ \\
\hline
\end{tabular}

Table 2. Fuel specification.

\begin{tabular}{cccc}
\hline Property & Diesel & stand & method \\
\hline Surfur content(ppm) & 19 & $\leq 50$ & GB/T380
\end{tabular}




\begin{tabular}{cccc} 
Cetane number & 52 & 51 & $\mathrm{~GB} / \mathrm{T} 386$ \\
Density at $20^{\circ} \mathrm{C}(\mathrm{kg} \mathrm{m}-3)$ & 841 & $820-845$ & $\mathrm{~GB} / \mathrm{T} 1884-1885$ \\
Distillation $50 \%$ by vol $\left({ }^{\circ} \mathrm{C}\right)$ & 258 & 300 & $\mathrm{~GB} / \mathrm{T} 6536$ \\
$95 \%$ distillation by vol $\left({ }^{\circ} \mathrm{C}\right)$ & 345 & 325 & $\mathrm{~GB} / \mathrm{T} 6536$ \\
Viscosity at $20{ }^{\circ} \mathrm{C}(10-6 \mathrm{~m} 2 \mathrm{~s}-1)$ & 4 & $4.0-6.0$ & $\mathrm{~GB} / \mathrm{T} 265$ \\
total aromatic $(\%$ by vol $)$ & 11 & 11 & $\mathrm{~GB} / \mathrm{T} 11132$ \\
\hline
\end{tabular}

\section{Experimental methods}

Altitude simulation system structure shown in Figure 1, which includes a climate control module, the fresh air supply module, the exhaust gas processing module and a control module. The altitude simulation system can control not only atmospheric pressure, but also temperature and modesty. The technical data are listed in Table 3

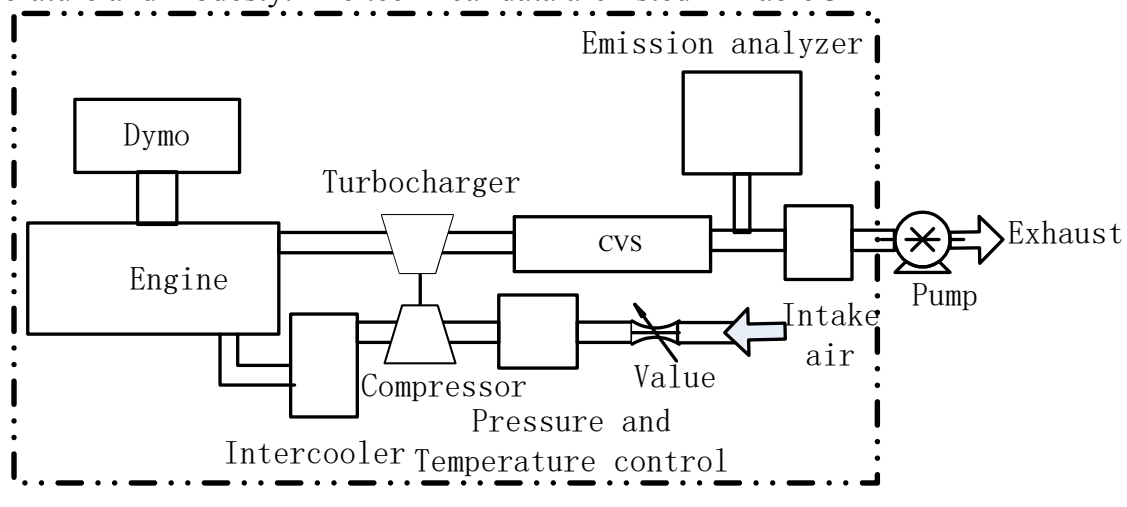

Cold-chamber

Fig. 1. Experiment setup.

Table 3. Engine specifications.

\begin{tabular}{ll}
\hline Reference & IMETCH \\
\hline Simulated altitude ranges $[\mathrm{m}]$ & $0 \sim 4500$ \\
Altitude precision $[\mathrm{m}]$ & $\leq \pm 50$ \\
Temperature ranges $\left[^{\circ}\right]$ & $-30 \sim 25$ \\
Temperature precision $\left[^{\circ}\right]$ & $\leq \pm 1^{\circ}$ \\
Humility ranges $[\% \mathrm{r} . \mathrm{h}]$ & $-30 \sim 90$ \\
Humility precision $[\% \mathrm{r} . \mathrm{h}]$ & $\leq \pm 1^{\circ}$ \\
\hline
\end{tabular}

The diesel engine emissions were sampled through the CVS system, then recorded by Horiba 7200 (HORIBA, Japan), and the opacity of the flue gas was measured with the aid of an opacity meter (AVL 415, Austria), while the combustion engine status was measured using the AVL combustion analyzer. Due to the low pressure at $4000 \mathrm{~m}$, the flue gas opacity cannot be sampled by AVL415 during the experiment. The flue gas opacity in this paper is only obtained at $0 \mathrm{~m}, 1000 \mathrm{~m}, 2000 \mathrm{~m}$ and $3000 \mathrm{~m}$. The formula for calculating the soot mass concentration is: Smoke opaque emission

$$
4 \mathrm{Cm}=20.8 \times \mathrm{Rb}+452.8 \times\left[\ln \frac{10}{10-R b}\right]^{2.042[1]}
$$


Cm was mass concentration of the Soot $\left(\mathrm{mg} / \mathrm{cm}^{3}\right)$.

\section{Analysis of test results}

\subsection{Brake specific fuel Consumption results at different altitudes}

The Brake Specific Fuel Consumption (BSFC) is shown in Figure 2. Due to the increment of simulated altitude, the intake air decreased and the fuel consumption had to be increased in order to maintain the same power output, which led to the increment of BSFC. From the figure it can be inferred that the effect of altitude on BSFC was obvious when altitude increased to $2000 \mathrm{~m}$, especially at high and low speed conditions, and the average increasing rate was $0.96 \% \sim 2.19 \%$ per $1000 \mathrm{~m}$.

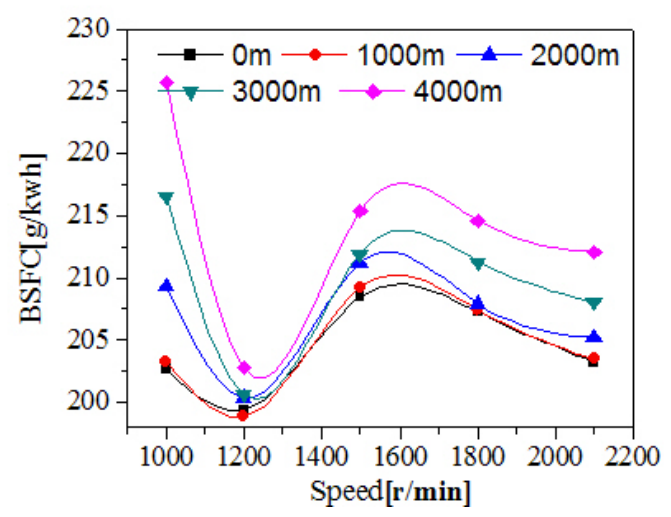

Fig. 2. BSFC of the engine at different altitudes.

\subsection{Emission results at different altitudes}

Figure 3 shows the emission condition of $\mathrm{NO}_{\mathrm{X}}, \mathrm{CO}$ and Soot at $100 \%$ load for different speeds with given simulated altitudes. As shown in the Figure, the emissions of $\mathrm{NO}_{\mathrm{X}}$ decreased, while the concentration of $\mathrm{CO}$ and Soot increased with altitude. The increase in fuel consumption and reduction in air density at high altitude resulted in the decrements of excess equivalence ratio, which contributed to the high emission of $\mathrm{CO}$. the increased combustion temperature and decreased air entrainment in cylinder favoured the formation of Soot, which resulted in the high emissions of Soot. On the country, the increasing altitude decreased the oxygen entrainment in cylinder, so the $\mathrm{NO}_{\mathrm{X}}$ formation was prohibited.
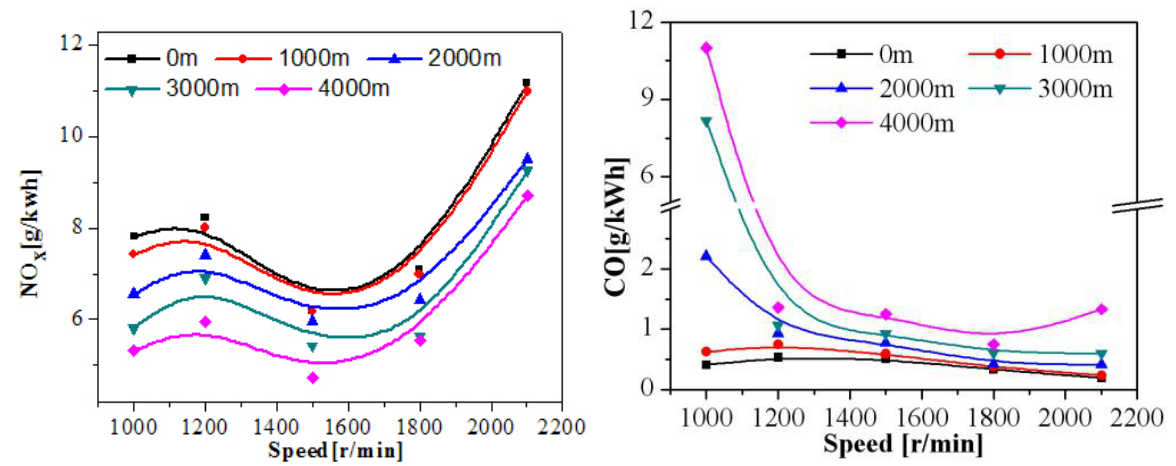


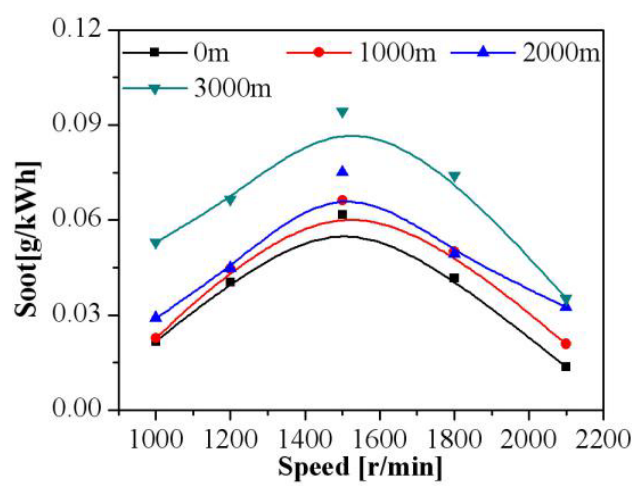

Fig. 3. Emission ((a) $\mathrm{NO}_{\mathrm{x}}$ (b) $\mathrm{HC}$ (c) $\mathrm{CO}$ (d) Soot) conditions at 100\% load.

\subsection{Increasing Rate of the Emission results at different altitudes}

Figure 4 shows the increasing rate (IR) of Soot, $\mathrm{CO}$ and $\mathrm{NO}_{\mathrm{X}}$ various different speeds. According tFig.o the Figure, it can be pointed that the IR of $\mathrm{CO}$ and $\mathrm{NO}_{\mathrm{X}}$ increased with altitude, while the increasing rate of Soot almost remained constant when altitude increased to $1000 \mathrm{~m}$ and $2000 \mathrm{~m}$. It can also be revealed that the effect of altitude on CO and Soot was greater than $\mathrm{NO}_{\mathrm{X}}$. The different impact of altitudes on the IR of emissions can be explained as follows: the decreased excess equivalence ratio and high temperature at high altitude both favoured the formation of $\mathrm{CO}$ and Soot. The impact of altitude of $\mathrm{NO}_{\mathrm{X}}$ was interaction result. The decreased excess equivalence ratio reduced the emissions of $\mathrm{NO}_{\mathrm{X}}$, while the high combustion temperature promoted the formation of $\mathrm{NO}_{\mathrm{X}}$ which in turn offset the decrements of $\mathrm{NO}_{\mathrm{x}}$. And so the increasing rate of $\mathrm{CO}$ and Soot was greater than those of $\mathrm{NO}_{\mathrm{X}}$.

With the increment of speed, the IR of CO, Soot first decreased and then increased. For all emissions of the engine, the effect of altitude was smaller at middle speed, and was greater at low and high speed can be explained as follows: at low speed exhaust energy was not enough to support the high efficiency work of turbocharger, which brought about the evident decrements of excess air coefficient, and finally led to the poor combustion at low speed. At high speed, the blow off valve was opened in order to protect the turbocharger, which reduced the effect of turbocharger. Based on the given reasons, the impact of altitude on the performance of emissions mainly inflected at low and high speeds, especially for the high speed. The minimum impact at medium speed can be explained as the consequence of character of turbocharger, which made the engine acquire maximum torque and the minimum decrements of decrements of equivalence ratio at medium speed.

$$
I R=\frac{(B-A)}{A} \times 100 \%
$$

B stands for the concentration of emission at high altitude and A stands for the concentration at low altitude. 

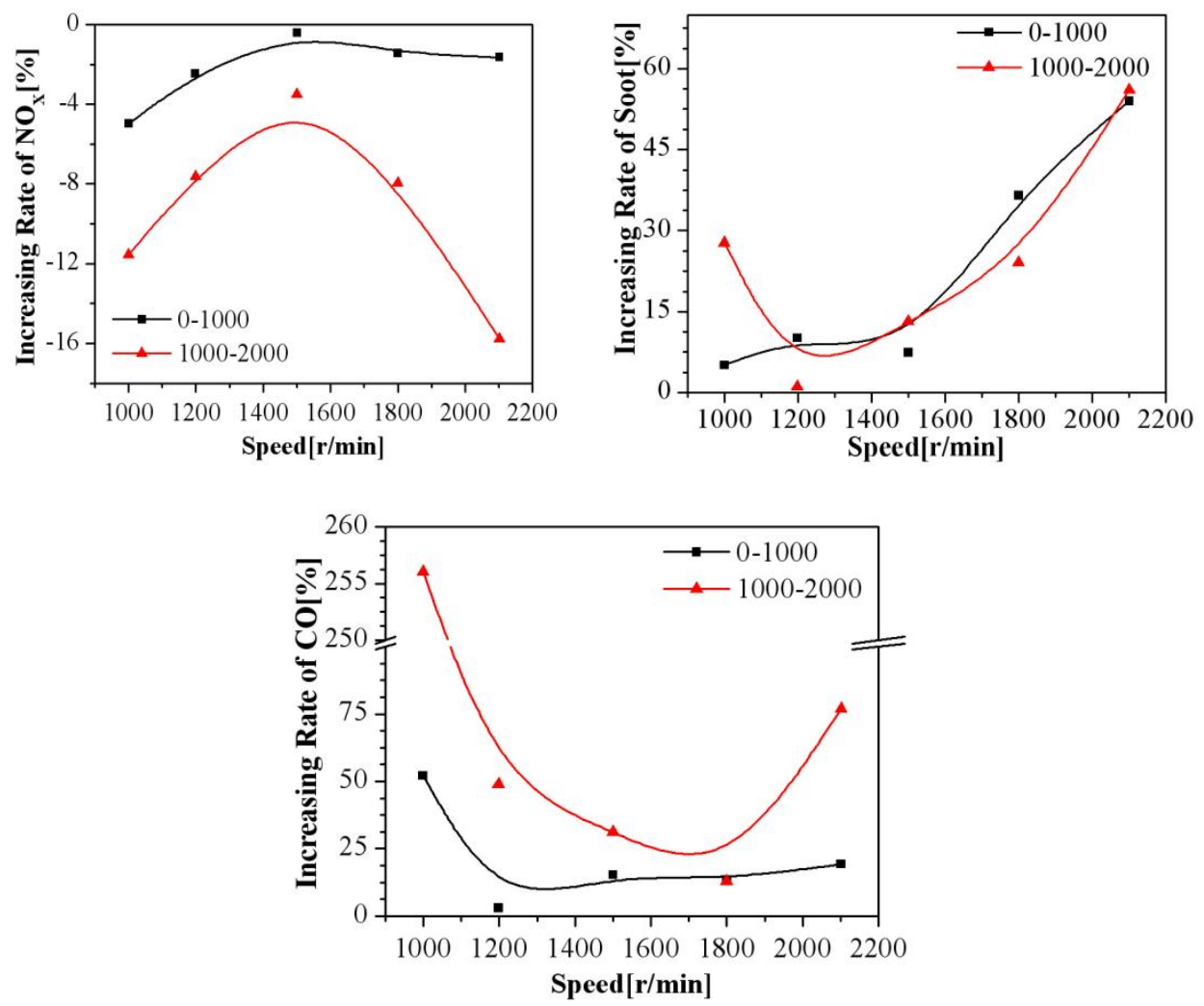

Fig. 4. Increment rate of Emissions ((a) $\mathrm{NOx}$ (b) Soot (c) CO) at 100\% load.

The concentrations of $\mathrm{NO}_{\mathrm{X}}, \mathrm{CO}$, Soot at 1200r/min are shown in Figure 5. According to the Figure the emissions of $\mathrm{CO}$ and Soot increased with altitude. When altitude increased from 0 to $2000 \mathrm{~m}$, the IR of CO was $15 \% \sim 150 \%$, and increased to $80 \% \sim 180 \%$ when altitude increased from $2000 \mathrm{~m}$ to $4000 \mathrm{~m}$. The change of NOX with altitude varied based on different loads: At low load $(200 \mathrm{Nm} \sim 400 \mathrm{Nm})$ the NOX emissions increased, while it decreased with altitude at middle and high loads.

According to the SIR that using simulated constant volume sampling (CVS) system to simulate altitude, the $\mathrm{NO}_{\mathrm{X}}$ emissions decreased under full load condition with increasing altitude. In this paper the same results came out under full load condition, while the IR was different due to the engine type and operation mode. For the emission condition at low load of $1200 \mathrm{r} / \mathrm{min}$, as will be discussed below. 

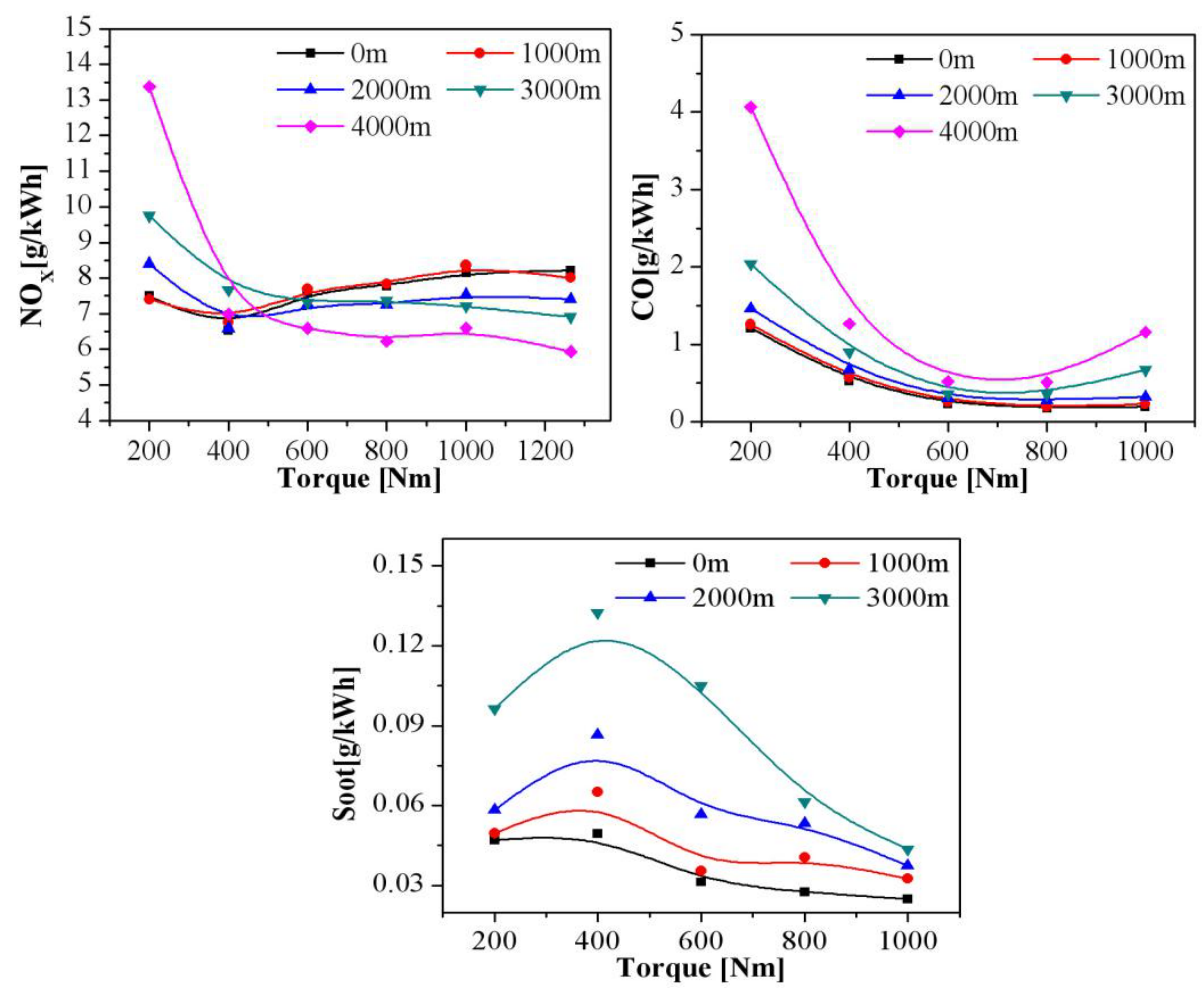

Fig. 5. Emission ((a) $\mathrm{NO}_{\mathrm{X}}$ (b) $\mathrm{HC}$ (c) $\mathrm{CO}$ (d) Soot) conditions at 1200r/min.

To exclude individual conditions impact the trends of the engine and ensure the accuracy and Repeatability of the experiment, the emissions of $\mathrm{NO}_{\mathrm{X}}$ at $200 \mathrm{Nm}$ and $400 \mathrm{Nm}$ for each speed are shown in Figure 6. As shown in the figure, $\mathrm{NO}_{\mathrm{X}}$ emissions increased with altitude at low speeds, while it decreased at high speeds with altitude, which verified the conclusion that the emissions of $\mathrm{NO}_{\mathrm{X}}$ decreased with altitude, while at low speed and low load it increased with altitude.
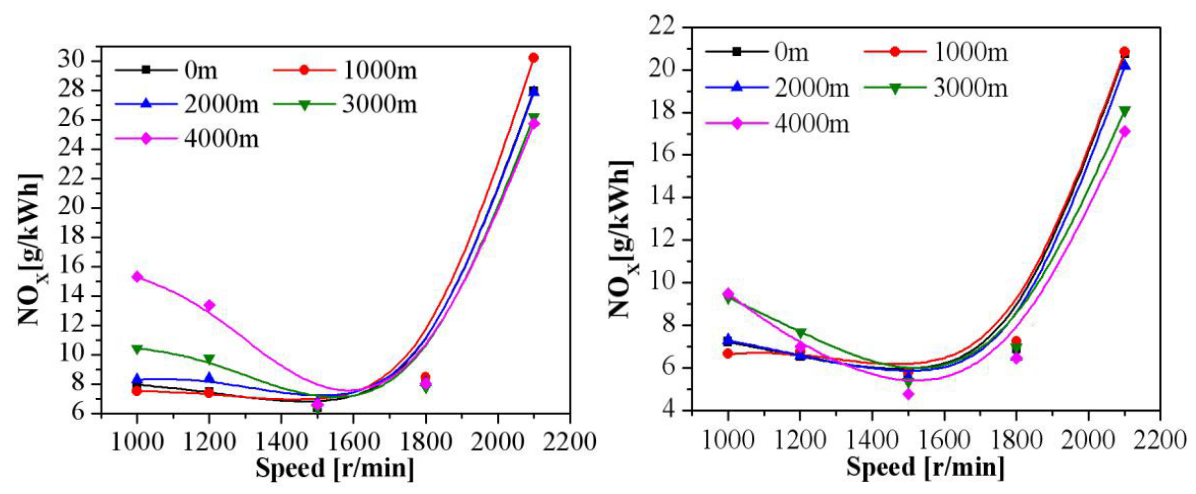

Fig. 6. NOx emissions at low load (a) $400 \mathrm{Nm}$ (b) $200 \mathrm{Nm}$.

The mean maximum combustion temperature and excess equivalence at $1200 \mathrm{r} / \mathrm{min}$ was shown in the figure 7. As shown in the figure, the maximum temperature increased while the excess equivalence decreased with altitude. It is well known that NO formation requires the presence of oxygen, high temperature and the reaction timing. On one side, the 
increasing altitude lead to smaller excess equivalence ratio which resulted in higher combustion temperature, thus the formation of NO was promoted. Meanwhile at low loads and low speeds, the intake swirl motion was weak, which may resulted in heterogeneous combustion and oxygen-enriched room can also promoted the formation of the NO. On the other side, the increasing altitude decrease the oxygen entrainment in cylinder, which resulting the deficient oxygen, especially at high load, so the formation of NO is prohibited. Furthermore, the intake swirl motion improved with the increment of speed, promoting the mixture of the combustion, and finally reducing the heterogeneous combustion of low load, which may explain the behaviour of NO decreased with altitude at low load of high speed.

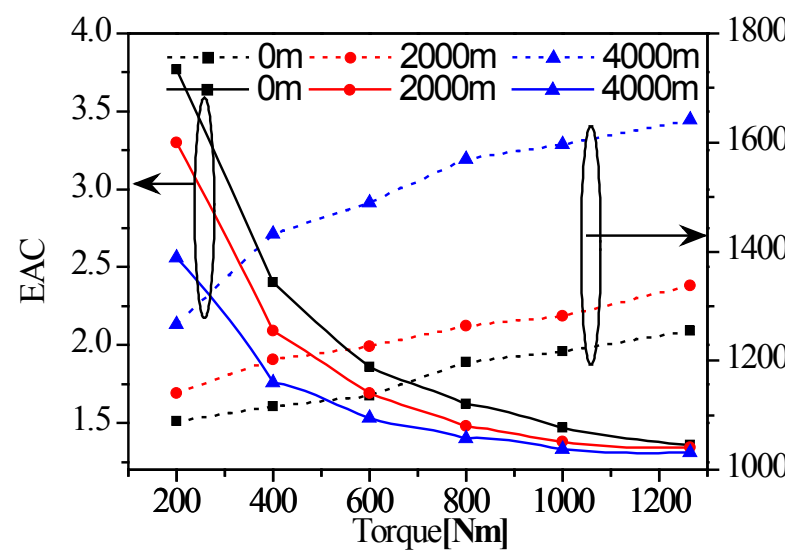

Fig. 7. The mean maximum combustion temperature and excess equivalence.

The average IR of the emissions is also calculated, as shown in Figure 8. Form the figure it can be included that, when altitude increased from 0 to $4000 \mathrm{~m}$, the IR of CO and Soot increased with altitude. The IR of NOX was positive at $1000 \mathrm{~m}$ while it keeps all negative when altitude increased to $2000 \mathrm{~m}$ and higher altitude. The above results are agreed with the emission change listed in table 6 . From the figure it can also included that the effects of altitude on CO and Soot emissions were greater than NOX. For all emissions, the minimum change of IR appears when altitude increased to 1000 .

Respectively, it may be inferred that there is a linear correlation between the altitudes and IR of the CO, and the average emissions of CO increased 14.5 59.5\% when altitude increased by $1000 \mathrm{~m}$. The IR of Soot was between $13.4 \%$ and $25.6 \%$ for increasing altitude for $1000 \mathrm{~m}$.

For emission conditions of the $\mathrm{NO}_{\mathrm{X}}$ it can be different, the emission increased was $1.0 \%$ at $1000 \mathrm{~m}$, while it decreased $-0.5 \% \sim-5.6 \%$ when altitude increased to $2000 \mathrm{~m}$ or higher altitudes.

The results presented here can have policy implications for public health and environment protection. Because the increased fuel consumption at high altitude produces more $\mathrm{CO} 2$, and the decreased excess equivalence ratio resulted in the increment of $\mathrm{CO}$ at high altitude. The more emissions emitted by vehicle exacerbated the greenhouse effect and vegetation impairment which contribute to affect the environment of high altitude. Meanwhile, the high concentration of $\mathrm{CO}$ and low content $\mathrm{O} 2$ enhance formation of carboxhemoglobin in human blood. Except for CO2 and CO, the soot emission also needed pay more attention, as reported by Chao He (2011), not only the mass emission of Soot increased with altitude, but also the number concentration increased, and the exhausted particles were smaller at high altitude. It is very known that the smaller and higher number 
particles emissions is associated with increased respoiratory disease, cardiopulmonary mortality and other potential health effects.

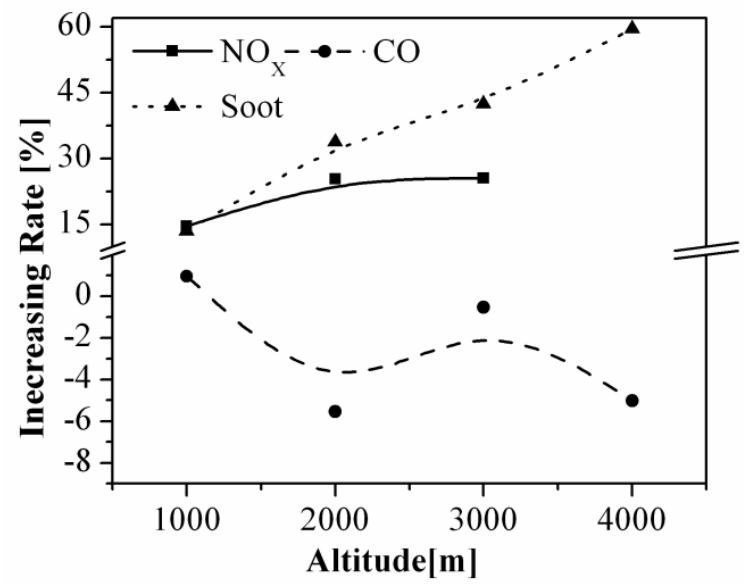

Fig. 8. Average Emissions of the engine at different altitudes.

\section{Conclusions}

The experiment was conducted to evaluate the impact of altitude on combustion and emission conditions of the engine, and the main results are summarized as follows:

1) The brake specific emissions of $\mathrm{NO}_{\mathrm{X}}$ varied under different operation conditions: at low load, NOX decreased with the increment of altitude, while it increased with altitude at middle and high loads. The IR of NOX increased when increasing the same altitude.

2) The average emission of $\mathrm{CO}$ and Soot increased with altitude, and the IR varied from $14.5 \sim 59.5 \% 13.4 \% \sim 25.6 \%$ respectively. Comparing to $0 \mathrm{~m}$, the average emissions of NOX increased at $1000 \mathrm{~m}$, while it decreased with altitude when increasing altitude to $2000 \mathrm{~m}$, and the IR was $-0.5 \% \sim-5.6 \%$.

3) The effects of altitude on $\mathrm{CO}$ and Soot emissions were greater than $\mathrm{NO}_{\mathrm{X}}$.

\section{References}

1. Brunekreef B; Holgate ST. Air pollution and health. Lancet 2002, 360, 1233 - 1242.

2. Brook RD; Franklin B; Cascio W, et al. Air pollution and cardiovascular disease: a statement for healthcare professionals from the Expert Panel on Population and Prevention Science of the American Heart Association. Circulation 2004, 109, 2655 2671.

3. Cancer Risk from Outdoor Exposure to Air Toxics. U.S. Environmental Protection Agency, Office of Air Quality Planning and Standards: Research Triangle Park, NC, 1990; EPA-450/1-90-004a, b.

4. Shen Lizhong.Study of Performance and Emissions of a Turbocharged Inter-Cooling Diesel Engine at Different Altitudes. Transactions of CSICE, 2006, 24(3), 250-255.

5. Lizhong, S., et al. Combustion process of diesel engines at region with different altitude. SAE Technology Paper. No.1995-01-0857. 
6. Agudelo, J., A. Agudelo and J. Perez, Energy and Exergy analysis of a light duty diesel engine operating at different altitudes. Revieta Facultad De Ingenieria Universidad De Antioquia, 2009, 48, 45-54.

7. Benjumea, P; J. Agudelo and A.Agudelo.Effect of altitude and palm oil biodiesel fuelling on the performance and combustion characteristics of a HSDI diesel engine. Fuel,2009. 88(4): 725-731.

8. Human,D.M.; T.L. Ullman; T.M. Baines. Simulation of high altitude effects on heavy-duty diesel emissions. SAE Technol, Pap. No.1994-01-0883.

9. Graboski Michael S, McCormick Robert L. Effect of Diesel Fuel Chemistry on Regulated Emissions at High Altitude[C]. SAE Paper 961974.

10. Bishop, G.A., et al., The effects of altitude on heavy-duty diesel truck on-road emissions. Environmental Science Technology. 2001. 35(8): p. 1574-1578.

11. He C, Ge Y, Ma C, et al. Emission characteristics of a heavy-duty diesel engine at simulated high altitudes[J]. Science of the Total Environment, 2011, 409(17): 3138-3143. 